\title{
Movimentos sociais, participação infantil e direitos da criança no Brasil
}

\author{
Maria Cristina Soares de Gouvêa ${ }^{1}$ \\ ORCID: 0000-0001-8023-1762 \\ Levindo Diniz Carvalho ${ }^{1}$ \\ ORCID: 0000-0001-5720-9268 \\ Isabel de Oliveira e Silva ${ }^{1}$ \\ ORCID: 0000-0003-2223-4548
}

\section{Resumo}

Este artigo analisa a participação da criança em ações coletivas, em diálogo com a produção acadêmica acerca do Movimento Nacional de Meninos e Meninas de Rua (MNMMR) e os Sem Terrinha, coletivo infantil vinculado ao Movimento dos Trabalhadores Rurais Sem Terra (MST). 0 texto busca desvelar a participação das crianças em cada movimento, na tensão entre os marcos legais sobre os direitos da criança e suas experiências concretas. Ao buscar compreender o significado de fazer os direitos das crianças em sua vida cotidiana, destaca-se, em cada movimento, a perspectiva da governança de direitos, da relação com o Estado e a dimensão política. Procurou-se discutir as concepções de participação e protagonismo tensionadas pelas relações hierárquicas de poder entre adultos e crianças, tanto na organização e gestão dos movimentos quanto na legitimação dos discursos. Assim, o trabalho contribui para as teorizações dos estudos dos movimentos sociais e de ações coletivas demonstrando que os conceitos de agência e participação não podem ser tomados como pressupostos apriorísticos, mas que demandam análise das condições e contradições para sua efetivação. Nessa direção, a compreensão da criança como ator social revela-se, em ambos os movimentos, como forma de superação do lugar de vítima para o lugar de sujeito que luta coletivamente por seus direitos.

\section{Palavras-chave}

Criança - Movimentos sociais - Participação infantil - Protagonismo.

1- Universidade Federal de Minas Gerais. Belo Horizonte, MG, Brasil.

Contatos: crisoares43@gmail.com; levindodinizc@gmail.com; isabel.os@uol.com.br

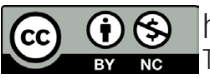




\section{Social movements, child participation and children's rights in Brazil}

\section{Abstract}

In this paper, the child participation in collective actions in dialog with the academic production about the Movimento Nacional de Meninos e Meninas de Rua (MNMMR) National Movement of Street Boys and Girls - and the Sem Terrinha - Little Landless -, a collective of children linked to the Movimento dos Trabalhadores Rurais Sem Terra (MST) - Landless Workers' Movement is analyzed. The text seeks to reveal the participation of children in each movement, in the tension between the legal provisions on the rights of the child and their concrete experiences. When seeking to understand the meaning of fulfilling children's rights in their daily lives, the perspective of rights governance, the relationship with the State and the political dimension stand out in each movement. The intent was to discuss the conceptions of participation and "protagonismo" faced by the hierarchical relations of power between adults and children, both in the organization and management of movements and in the legitimation of discourses. Thus, the work contributes to the theories of the studies of social movements and collective actions, since it demonstrates that the concepts of agency and participation cannot be taken as a priori assumptions, as they demand analysis of the conditions and contradictions for their effectiveness. In this direction, the understanding of the child as a social actor is revealed, in both movements, as a way of overcoming the victim mentality in order to occupy the place of a subject who collectively fights for his/her rights.

\section{Keywords}

Child - Social movements - Child participation - Protagonismo.

Este artigo analisa a participação da criança em ações coletivas, em diálogo com a produção acadêmica a respeito do Movimento Nacional de Meninos e Meninas de Rua (MNMMR) e os Sem Terrinha, do Movimento dos Trabalhadores Rurais Sem Terra (MST).

Busca-se contribuir para a compreensão da participação da criança na vida social, considerando-se sua inserção em movimentos sociais e ações coletivas. Ancorados na perspectiva de Liebel (2012), que propõe a análise da participação da criança não a partir dos textos normativos, mas de experiências concretas (participation from bellow), caracterizamos cada Movimento e sua participação na luta pela proteção dos direitos infantis, confrontando-a com as concepções predominantes no documento da Convenção sobre os Direitos da Criança (CDC), do Fundo das Nações Unidas para a Infância (UNICEF, 1989). Observa-se que a criança é praticamente ausente nas teorizações sobre ator e ação social nos estudos dos movimentos sociais; além disso, a análise da participação da criança 
em ações coletivas mostra-se lacunar nos estudos da infância. ${ }^{2}$ Buscamos, neste artigo, dialogar com ambos os campos na análise de experiências de participação.

0 estudo foi construído com base em dados secundários, gerados a partir da literatura, a respeito dos dois Movimentos: teses, artigos ou capítulos e livros. Analisamos a relação entre elementos da agência infantil no MST (ARAUUJ0, 2007; BARROS, 2013; CORREIA; GIOVANETTI; GOUVÊA, 2007; FREITAS, 2015) e no MNMMR (COSTA, 1998; MNMMR, 1985, 1995; MNMMR/UNICEF, 1995; PEREIRA, 2011) e o quadro teórico contemporâneo acerca de movimentos sociais e ações coletivas (TOURAINE, 1997; MELUCCI, 1996; GOHN, 1998; DOIMO, 1993) e a respeito dos direitos da criança e sua participação (FERGUSON, 2013; GOUVEA et al., 2019; LIEBEL, 2012; PILOTTI; RIZZINI, 1995; ROSEMBERG; MARIANO, 2010).

Não pretendemos uma análise comparativa, mas buscamos destacar as singularidades da participação infantil nesses dois movimentos. Assim sendo, este artigo está estruturado da seguinte forma: inicialmente, dialogamos com os referenciais teóricos de análise de movimentos sociais e ações coletivas, contemplando especialmente o conceito de ator; em seguida, analisamos a emergência de movimentos sociais no Brasil pós-ditadura de 1964, dentre os quais estão o MST e o MNMMR; analisamos a produção dos estudos da infância sobre participação e agência da criança na formulação e avaliação do documento da CDC. Posteriormente, analisamos as concepções de participação da criança em cada movimento, destacando a discussão acerca da autonomia infantil no interior de relações de poder com adultos.

\section{Movimentos sociais, ações coletivas e agência infantil}

Os estudos da infância afirmam a agência das crianças por meio das noções de ação social, ator social e sujeito. Esses estudos compreendem que crianças são atores sociais, sujeitos ativos na construção de suas vidas, na relação com outras crianças e adultos e com a sociedade, ainda que submetidas aos condicionantes das estruturas sociais (JAMES; PROUT, 2015). Mayall (2002) traz para a análise da infância a distinção, estabelecida por Giddens, entre ator e agência. As crianças seriam atores sociais, porque atuam no mundo. Já a agência pressupõe a capacidade de intervir na realidade, transformando-a (MAYALL, 2002). No entanto, para Spyrou (2018), tal distinção não se faz presente em grande parte dos estudos do campo, sendo a agência essencializada, considerada uma propriedade da criança. Para o autor, conceitos formulados para analisar as ações dos adultos são transpostos para a compreensão da experiência de crianças e adolescentes.

Considerar as crianças como atores sociais requer entender que suas ações são regulamentadas por um sistema de normas comuns reconhecido como válido (LADRIĖRE, 1971) e que suas ações têm sentidos subjetivamente orientados nas relações das quais participam (COHN, 1979). No entanto, essa forma de analisar a ação social é marcada pela racionalidade adulta, a partir da qual tal noção foi elaborada. Tal como formulada, ela supõe um grau de autonomia e liberdade que não se verifica para esse grupo geracional.

2 - Na obra Palgrave handbook of childhood studies (QVORTRUP; CORSARO; HONIG, 2010) não se faz qualquer referência à participação da criança em movimentos sociais. 
A compreensão de experiências de participação coletiva de crianças exige considerar a tensão entre proteção e autonomia. Nessa direção, compreender a participação de crianças e adolescentes em ações coletivas apoiadas por grupos adultos requer a discussão de suas características e do seu alcance, tendo em vista a condição geracional e as assimetrias de poder. Requer, também, a explicitação dos sentidos de movimentos sociais e ações coletivas quando referidos à participação social de crianças e adolescentes.

Argumentamos que, mesmo submetidas ao controle adulto, crianças e adolescentes revelam agência em suas experiências individuais e coletivas. No entanto, consideramos que não se pode realizar uma transposição direta desses conceitos para a compreensão da experiência infantil (SANTOS; SILVA, 2016). Por essa razão, discutimos as noções de ação coletiva e movimento social para, em seguida, indicar a forma pela qual as entendemos referidas ao Movimento Nacional de Meninos e Meninas de Rua e aos Sem Terrinha.

Os conceitos de movimentos sociais e ações coletivas ancoram-se no reconhecimento de que os atores, ${ }^{3}$ de forma mais ou menos consciente, disputam o controle ou buscam transformar suas imagens e as do campo no qual se encontram.

Touraine (1996, p. 59) advoga que as sociedades contemporâneas são definidas menos por instituições, por um poder central e por valores ou regras permanentes, do que por esse campo de disputas, cujo desafio é a "utilização social dos bens simbólicos nelas produzidos" - os quais se relacionam com a própria definição das formas de reprodução social, de produção e de desenvolvimento social. Nessa perspectiva, o autor eleva o ator ao centro das análises da vida social que, para ele, deve ser compreendida por meio da multiplicidade de sistemas que a constituem e dos conflitos entre os diferentes grupos. Destaca, no entanto, que os conflitos que constituem os sistemas sociais não eliminam o conflito social central, que se expressa na luta pelo controle da historicidade, ou seja, pelo controle da capacidade de a sociedade operar transformações sobre si mesma. Com essa perspectiva, o autor confere papel central às ações coletivas que podem, ou não, se converter em movimento social que é, para ele, o ator coletivo que se põe em disputa pela historicidade.

$\mathrm{Na}$ mesma direção, Melucci (1996) entende a ação coletiva como produto de processos sociais heterogêneos. 0 autor reconhece que a ação coletiva é parte de um campo de relações com múltiplos significados e demandas frequentemente contraditórias. Esse autor sustenta que os conflitos são múltiplos e somente podem ser explicados a partir das relações sociais nas quais eles são produzidos.

Para Melucci (1996), as sociedades complexas comportam tipos específicos de relações sociais que caracterizam seus múltiplos sistemas: o sistema que assegura a produção dos recursos societais e envolve relações antagonistas; o sistema de decisões sobre a distribuição desses recursos - o sistema político; o sistema de papéis que governa as trocas e o desenvolvimento, ou seja, o sistema organizacional que assegura o equilíbrio interno, por meio dos processos de integração; e o mundo da vida, ou sistema de reprodução da vida cotidiana. Para ele, a distinção desses níveis de análise permite compreender os fenômenos de ação coletiva sem encerrá-los na noção genérica de movimento social. Esse se caracterizaria, então, como uma categoria que designa a ação coletiva que invoca uma

$\mathbf{3}$ - Não iremos trabalhar com a distinção entre ator e agência de Giddens, porque esta não se faz presente nos teóricos dos movimentos sociais e ações coletivas com os quais dialogamos neste texto. 
solidariedade, faz manifestar um conflito e acarreta a quebra dos limites de compatibilidade do sistema em que a ação acontece. Por quebra dos limites de compatibilidade, o autor entende a situação em que a ação empurra o conflito para além dos limites do sistema de relações sociais no qual a ação está localizada, em que se colocam objetivos não-negociáveis e se desafiam as relações de poder.

A mobilização dos construtos ação coletiva e movimento social, para a compreensão dos fenômenos analisados neste artigo, permite operar com a ideia de que a luta pelos direitos das crianças integra múltiplos conflitos que incluem as relações geracionais e de classe. Essa luta reuniu diferentes atores individuais e coletivos, nos planos nacional e internacional, na disputa pela construção simbólica da criança e da infância e pela direção das políticas a elas dirigidas. A participação das crianças na vida social e nos assuntos que lhes dizem respeito é um dos direitos consagrados no plano internacional pela CDC e, no plano nacional, pelo Estatuto da Criança e do Adolescente - ECA (BRASIL, 1990). 0 ECA, reconhecido como a expressão de uma nova doutrina da infância, é resultado de lutas e mobilizações sociais que incluíram, de forma coletiva no MNMMR, crianças e adolescentes apoiados por organizações que atuavam na defesa de seus direitos. Da mesma forma, apoiados pelos adultos do MST, efetivou-se, em seu interior, um processo de organização das crianças - os Sem Terrinha - cujos direitos são, dentre outras questões, objeto das ações das quais participam.

De um lado, essas duas ações podem ser caracterizadas como ações coletivas, à medida que manifestam organização, solidariedade e luta por bens simbólicos. De outro lado, que não se trata de movimentos sociais na acepção discutida acima, pois não colocam em xeque os limites de compatibilidade do sistema social das relações geracionais.

Constituem-se, no entanto, marcadas por processos identitários da condição geracional e pela situação de exclusão social. Elaboram suas demandas e constroem espaços e tempos de sociabilidade e de exercício de uma solidariedade. É com essa perspectiva que consideramos as crianças e adolescentes do MNMMR e os Sem Terrinha como atores sociais. De um lado, apoiamo-nos na literatura referente aos estudos sociais da infância e em pesquisas que observam que as crianças são atores que interpretam o mundo e, diante de determinadas condições, são agentes de transformação (MAYALL, 2002). De outro lado, não conferimos a essa agência a mesma autonomia dos adultos. Isto significa reconhecer as hierarquias geracionais que não apenas podem dar a direção da ação, como tolher ações originadas do universo infantil.

\section{Direitos da criança e movimentos sociais no Brasil}

A partir dos anos 1970, emergem no Brasil ações coletivas voltadas para a melhoria das condições de vida, o que Sader; Paoli (1986) denominam como a entrada em cena de novos personagens. Tendo como objeto a luta por direitos, os "novos movimentos sociais" (GOHN, 1985) se constituíram fora dos espaços tradicionais, com a ideia de democracia de base com independência dos partidos políticos (ASSIES, 2016). As organizações não governamentais (ONGs) constituíram setor importante desse campo, compartilhando os princípios da autonomia, independência e democracia de base (DOIMO, 1993). Tais ONGs 
desenvolveram ações que contribuíram para a incorporação, na Constituição Federal de 1988, de formas de cooperação entre Estado e sociedade civil (OLIVEIRA; HADDAD, 2001).

Já os movimentos sociais do campo retomam, nesse período, a bandeira da reforma agrária anterior a 1964, com ações coletivas de luta pela terra. Nos anos 2000, observa-se que os movimentos sociais do campo incorporam, dentre outras temáticas, a preocupação com as práticas educativas e as questões de gênero e geração (MIRANDA; FIÚZA, 2017), em um processo de aprofundamento e ampliação de suas agendas.

No plano internacional, o Brasil participou da elaboração da Convenção Internacional dos Direitos da Criança (CDC), cuja representação contou com a assessoria de movimentos de defesa da infância (PILOTTI; RIZZINI, 1995). Esses movimentos tiveram também forte participação nas ações que culminaram na elaboração do Estatuto da Criança e do Adolescente de 1990 (BRASIL, 1990). O ECA constitui tanto um desdobramento do texto da Constituição de 1988 quanto da CDC, sendo ambos os documentos, até hoje, balizadores das discussões e políticas sobre direitos das crianças no País.

\section{O princípio da participação e a Declaração Universal dos Direitos da Criança}

É inegável que a CDC é um marco legal determinante na apreensão jurídica da infância. Uma das novidades foi a introdução do princípio da participação infantil. Grande parte da literatura a respeito do tema centrou-se nesse princípio, discutindo seus avanços e contradições (FERGUSON, 2013; REYNOLDS; NIEUWENHUYS; HANSON, 2006; TOBIN, 2013; LIEBEL, 2012; QUENNERSTEDT, 2013). Destacam-se as críticas à ausência das crianças na formulação do texto (REYNOLDS et al., 2006), à indefinição do conceito de participação (TOBIN, 2013) e dos mecanismos para sua promoção (LIEBEL, 2012), desconsiderando a singularidade das formas de expressão da criança. 0 modelo de participação é especialmente criticado por ancorar-se na experiência das crianças dos países do Hemisfério Norte, tomada como universal, não incorporando as formas de participação das crianças do chamado Sul Global (ROSEMBERG; MARIANO, 2010; MARCHI; SARMENT0, 2017). Ao mesmo tempo, discutem-se as tensões entre os princípios da proteção e da participação (LIEBEL, 2012).

0 princípio da proteção, tal como formulado no documento, tem sido objeto de críticas ao atribuir, exclusivamente à criança, vulnerabilidade e dependência ontológicas, como se essas características não se fizessem presentes na vida adulta como dimensões do humano (LEE, 2001).

Ainda que a vulnerabilidade e a dependência das crianças em relação aos adultos sejam inequívocas, as relações intergeracionais caracterizam-se por uma interdependência entre adultos e crianças, especialmente visíveis em situações de pobreza.

Observa-se que a concepção privatista de proteção da criança, presente no documento da CDC, que restringe a vida social aos espaços da família e da escola, choca-se com experiências de circulação e participação na vida urbana, em atividades de trabalho e lazer características das camadas populares latino-americanas (PARGA, 2004; LIEBEL, 2012). 
Já o princípio da participação é compreendido, no documento, como escuta individual, circunscrito a temáticas entendidas como pertinentes ao universo infantil, como escola e lazer. A participação social não é considerada uma dimensão presente na vida da criança no exercício de sua cidadania, mas como um processo formativo para algo a ser efetivado na vida adulta (ROSEMBERG; MARIANO, 2010; MARCHI; SARMENTO, 2017). Para Milne (2015, p. 10), "a participação das crianças do Hemisfério Norte embasou uma agenda para o restante do mundo sem maior conhecimento das experiências das crianças em movimentos do chamado Sul Global."

As críticas refletem as condições de produção do documento, que reproduziram relações de poder entre os países signatários com participação marginal dos países periféricos (TOBIN, 2013), o que se refletiu no texto final (PILOTTI, 2000).

Buscando a compreensão das diferentes formas de participação, Liebel (2012) propõe pensá-la não a partir do texto normativo do CDC, mas das experiências de crianças em contextos socioculturais que informam sua singularidade. Liebel (2012) observa que nos movimentos sociais de defesa de direitos das crianças latino-americanas é frequente o uso do termo protagonismo, em vez de participação, destacando a centralidade da criança na luta por seus direitos, termo ausente em outros $\operatorname{contextos}^{4}$ (GOUVEA et al., 2019).

Com essa perspectiva, analisaremos o processo de constituição do MNMMR em que as crianças atuaram diretamente na definição e defesa de direitos, na relação com adultos, e na construção do documento do ECA. Em seguida, discutiremos a produção relativa às crianças Sem Terrinha, focalizando a emergência do movimento e destacando as formas de participação das crianças.

\section{Movimento Nacional de Meninos e Meninas de Rua: protagonismo e institucionalização}

O MNMMR nasceu em 1982 e se constituiu como uma entidade civil independente, em 1985. Foi idealizado por ONGs, educadores e políticos, em diálogo com crianças e jovens em situação de rua e se instituiu como um dos movimentos que aliavam a luta pela cidadania política à superação de processos de exclusão socioeconômica. Ancorava-se em identidades plurais, como gênero, raça, local de moradia e, no caso dos meninos em situação de rua, geração. À semelhança dos demais movimentos sociais, o MNMMR estabeleceu como estratégia intervir nos espaços institucionalizados, no contexto de elaboração da Constituição de 1988. O MNMMR integrava o Movimento Criança e Constituinte, ação coletiva que pautava os direitos da criança no texto da Constituição de 1988. Resultado dessa luta, o texto final, pela primeira vez, imputava ao Estado a responsabilidade pela proteção, dignidade e respeito à criança, ampliando seus direitos no reconhecimento das especificidades da infância (COSTA, 1998).

0 surgimento do MNMMR relaciona-se à significativa ampliação do número de crianças e de jovens em situação de rua nas grandes cidades e à ineficácia das políticas sociais. 0

4- Curiosamente, Liebel (2012) usa o termo protagonismo em português, afirmando que o mesmo seria de difícil tradução para a Língua Inglesa. 
Movimento sustentava-se nas experiências de vida dessas crianças, entendendo-as como atores sociais, cuja participação seria essencial na formulação e na conquista de direitos.

Inicialmente, as ONGs e as pesquisas acadêmicas construíram um retrato desses meninos e meninas como privados da infância, ora associando-os à criminalidade ora destituindo-os da condição de sujeitos (UNICEF, 1987; DIMENSTEIN, 1992). A literatura a respeito dessa experiência indica que as crianças desenvolviam práticas lúdicas, bem como demandavam proteção e cuidado dos adultos. Nesse sentido, não se tratava de uma não infância (HUGHES; HOFFMAN, 1997), mas de uma agência infantil que tensionava os modelos dominantes (ROSEMBERG, 1993). A presença dessas crianças na cena social e sua participação no Movimento colabora para a ruptura com uma visão da criança em situação de rua atrelada exclusivamente à criminalidade.

No seu cotidiano, as crianças desenvolviam redes de solidariedade e sociabilidade, por meio das quais buscavam se defender da violência cotidiana que lhes era imposta. ${ }^{5}$ Ainda que em sua maioria mantivessem vínculos afetivos com a família, retornando ao domicílio de origem, exerciam liberdade e autonomia, vivendo a maior parte no tempo nas ruas (ROSEMBERG, 1993). ${ }^{6}$

0 principal objetivo do Movimento era a construção de instâncias de organização desses atores. 0 MNMMR foi estruturado por núcleos de base, cogeridos pelos próprios meninos e meninas, em que debatiam, entre si e com adultos, a condição social de excluídos; adquiriam conhecimentos que os qualificassem para a conquista de seus direitos e elaboravam projetos alternativos para as suas vidas. 0 Movimento organizavase em quatro projetos: Conquista de Direitos e Defesa da Criança e do Adolescente; Formação e Organização de Meninos e Meninas; Formação de Educadores; Fortalecimento e Interiorização do Movimento. ${ }^{7}$

A partir de sua experiência, crianças e adolescentes reivindicavam proteção e cuidado, e demandavam o direito à gestão de suas vidas, rompendo com uma perspectiva que contrapõe autonomia à proteção, e superando, no que concerne à participação, a concepção apontada pela CDC, circunscrita à escuta individual das crianças.

A construção de instâncias participativas, sobretudo nos encontros, possibilitou o exercício da prática democrática, em que as crianças elegiam seus representantes e elaboravam estratégias de ação. Evidentemente, tais instâncias eram atravessadas por relações intergeracionais de poder, tendo as ONGs decisiva atuação na organização e gestão do Movimento. As estratégias de mobilização e organização dos encontros e fóruns reproduziam, muitas vezes, dinâmicas adultocentradas, atravessadas por jogos de alteridade entre crianças e agentes sociais, e lideranças que atuavam no Movimento. ${ }^{8}$

5- Umas das principais reivindicações era o fim do assassinato, violência e agressão de crianças (SUDBRACK, 2014), bem como das mais diversas formas de violência e agressão de que eram vítimas por adultos, especialmente das forças policiais.

6- Essa perspectiva redundou na mudança na denominação desses sujeitos. De meninos e meninas de rua, passou-se a utilizar o termo meninos e meninas em situação de rua, de forma a dar visibilidade ao caráter transitório de sua presença nas ruas.

7- Em 1992, o MNMMR contava com "90 comissões locais estruturadas, 139 números de base de meninos e de programas, cerca de três mil militantes, e três centros de formação para educadores de rua. E existia mais de 400 programas de atendimento ligado ao Movimento" (FALEIROS, 1995, p. 89).

8- Na V Conferência de Direitos da Criança e do Adolescentes, realizada em 2005, foi produzida a Carta aberta dos adolescentes participantes, na qual reivindicavam que estes eventos assumissem um caráter mais lúdico, bem como tivessem maior poder decisório (LAZZARETTI DE SOUZA et al., 2010). 
A realização, em 1986, do I Encontro Nacional de Meninos de Rua, ${ }^{9}$ em Brasília/ DF, possibilitou dar voz às crianças em suas demandas e à organização nacional do Movimento, quando se estabeleceu sua regionalização em cinco polos pelo país. ${ }^{10}$

A partir desse I Encontro, o MNMMR concentrou suas ações na luta pela construção de um aparato legal que promovesse os direitos da criança em situação de rua e garantisse sua proteção pelo Estado. No II Encontro, realizado em 1989, priorizou-se a atuação política no Congresso Nacional, com a discussão e aprovação simbólica do ECA, que ocorreu numa cerimônia de votação do Estatuto com forte representatividade na afirmação do protagonismo infantil na formulação do documento. Naquele dia, 750 meninos e meninas ocuparam o Congresso Nacional, discursaram e votaram simbolicamente o texto final, ratificado pelos congressistas, em 1990.

Por meio dessas e de outras ações, o MNMMR participou diretamente da formulação do ECA. 0 Estatuto, por um lado, incorporou em seu texto os princípios básicos da CDC. Por outro lado, construiu referências para a política de proteção às crianças brasileiras em situação de vulnerabilidade, a partir dos direitos conquistados na Constituição de 1988. 0 ECA institui a chamada doutrina da proteção integral das crianças e adolescentes, superando a lógica punitiva e conferindo-lhes o status de cidadãos.

0 processo de formulação do ECA permitiu interrogar o conceito de participação presente na CDC, revelando estratégias coletivas de participação da criança. 0 Estatuto indica como direito fundamental da criança a participação na vida familiar e comunitária, sem discriminação (artigo 16, V); a participação da vida política, dentro dos limites legais (artigo 16, VI); e a organização e participação em entidades estudantis (artigo 53, IV). 0 protagonismo na conquista dos direitos das crianças e dos adolescentes, entendidos como atores políticos, sinaliza um modelo de participação como dimensão inerente à sua experiência social. ${ }^{11}$

0 ECA instituiu, ainda, a inimputabilidade penal de crianças e jovens menores de 18 anos, bem como a criação de órgãos de acompanhamento e efetivação das políticas para a infância, com participação da sociedade civil. Destaca-se a criação dos Conselhos Tutelares, órgãos públicos municipais autônomos, constituídos por membros eleitos da sociedade civil, encarregados de acompanhar e encaminhar à rede de proteção casos de crianças e adolescentes em privação de direitos e em conflito com a lei. Destaca-se, também, a criação dos Conselhos de Direitos da Criança e do Adolescente, constituídos por representantes do poder público, sociedade civil e terceiro setor, responsáveis pela fiscalização, debate e acompanhamento do cumprimento do ECA. ${ }^{12}$

\footnotetext{
9- № ano de 1984, com apoio da UNICEF, foram organizados vários encontros que culminaram no / Seminário Latino-Americano de Alternativas Comunitárias de Atendimento a Meninos e Meninas de Rua, em Brasília/DF, importante marco de mobilização para criar o MNMMR. Com base em experiências bem-sucedidas, o objetivo foi formar/mobilizar/conscientizar os/as meninos/as à própria participação do debate sobre seus direitos (PILOTTI; RIZZINI, 1995).

10- 0 Movimento foi estruturado em comissões de nível local, estadual e nacional, contando com 100 comissões locais, 23 comissões estaduais e um Conselho Nacional.

11- Aprovada, mais recentemente, a Lei $n^{0} .13 .257 / 2016$ - Marco Legal da Primeira Infância - que prevê que as políticas públicas voltadas para a primeira infância também devem "incluir a participação da criança na definição das ações que lhe digam respeito, em conformidade com suas características etárias e de desenvolvimento" (BRASIL, 2016, artigo 4" II).

12- Cabe destacar a recente visibilidade da temática dos direitos das crianças e do papel dos representantes no Conselho Tutelar na eleição para seus membros no ano de 2019. A questão ganhou destaque nas mídias e no debate público, reativando mecanismos de participação da sociedade civil e refletindo a polarização presente nas eleições para o Executivo nacional e estadual.
} 
Tais instâncias constituem-se como órgãos do sistema de garantia de direitos da criança no Brasil. Em alguns casos, fomentam a participação de crianças, por meio de conferências infantis, em que se pautam os direitos das crianças a partir de suas próprias vozes. Entretanto, essas iniciativas ainda são exceção no contexto brasileiro - o que confirma o desafio do reconhecimento das crianças como atores sociais, como preconiza o marco legal.

A criação dos conselhos tutelares e dos conselhos de direitos da criança institucionalizaram novos modelos de governança dos direitos da criança. 0 ECA, ao mesmo tempo em que imputa ao Estado a proteção da criança em situação de rua, com a criação de espaços e instâncias de cuidado, atribui à sociedade civil o acompanhamento local e nacional da efetivação das políticas. Afırma-se um modelo de governança que reforça o papel de um Estado voltado para o bem-estar social, aliado à gestão democrática e regionalizada.

No entanto, como afirma Pilotti (2000), a efetivação da CDC nos países latinoamericanos centrou-se na construção de marcos legais, com excessiva formalização que deu menos atenção às estruturas de dominação que sustentam as desigualdades.

Os estudos do campo indicam o desafio da articulação de redes e do fortalecimento do sistema de garantia de direitos. No contexto atual de crise social e política, assiste-se ao esvaziamento dos programas de proteção da infância e à pressão de grupos pelo fim da inimputabilidade penal.

Os dados mais recentes indicam rápida deterioração das condições de vida da criança no Brasil após 2016, resultante da recessão econômica, do sucateamento das políticas e do desmonte das redes de proteção social, quadro que piora dramaticamente com a chegada ao poder do governo Bolsonaro, que já apresentava, em sua pauta, o desmonte do ECA e a destruição dos movimentos sociais, questões que vêm contemplando em seu governo. Observa-se, assim, a fragilidade das conquistas de direitos pela criança, em um país onde a democracia é ainda recente e a desigualdade sociorracial histórica e persistente.

\section{O Movimento dos Trabalhadores Rurais Sem Terra (MST) e os direitos das crianças}

O Movimento dos Trabalhadores Rurais Sem Terra (MST) resulta das lutas sociais que ganharam corpo no Brasil na década de 1970 (ARAÚJO, 2007), estruturando-se em 1984 (BARROS, 2013). O MST é o principal movimento social de luta pela Reforma Agrária no Brasil. Tem um conjunto de ações articuladas que envolve o embate político direto, ocupações de terras pertencentes a grandes latifúndios e, mais recentemente, a grandes empresas do agronegócio (ROSSETO, 2016).

Com o desenvolvimento e a consolidação de suas ações, esse Movimento trabalha também na construção simbólica de reconhecimento das suas formas de luta, por meio de práticas culturais, rituais e formas de sociabilidade de valorização da terra, da vida no campo e da cultura das populações rurais, tendo como objetivo histórico a construção do projeto socialista de sociedade (ARAÚJO, 2007). 
Para Barros (2013, p. 20), no âmbito simbólico da produção de identidades sociais individuais e coletivas, "ser e agir como Sem Terra em luta é uma das principais maneiras que os camponeses encontraram para a construção de suas histórias.”

Em pesquisa que ouviu crianças de um acampamento de Sem Terra (CORREIA; GIOVANETTI; GOUVÊA, 2007), observa-se que as experiências das crianças com os adultos e entre si possibilitam a compreensão dos próprios contextos de vida e dos significados da luta coletiva pela terra, acompanhando situações de tomada de decisões, o que inclui situações de enfrentamento com a polícia e donos da terra e, também, os trâmites jurídicos em curso. Assim, a participação das crianças no MST pode ser apreendida pela sua posição na família, que é sujeito e beneficiária da conquista da terra, quando ela ocorre. No entanto, internamente, o MST se verá confrontado com a participação das mulheres, dos jovens e das crianças, estas últimas como um sujeito com particularidades - o que inclui linguagens próprias de expressão de suas necessidades e desejos (FREITAS, 2015).

A vivência da infância, marcada pela pobreza que caracteriza o campo brasileiro, torna-se tema de luta e de produção simbólica dentro do Movimento. A ausência de escolas também trará a discussão dos direitos das crianças à escola para a pauta de luta do MST, embora, para o Movimento, desde o início, a educação ultrapassa a ideia de educação escolar (BARROS, 2013). 0 direito à educação como bandeira do MST é compreendido nos estudos sobre o Movimento como parte da luta pela terra e pela Reforma Agrária. 0 MST reivindica o direito à educação escolar nos assentamentos da Reforma Agrária, articulando a luta pela terra à luta pelo acesso ao conhecimento, denunciando a exclusão dos trabalhadores dos direitos básicos fundamentais.

A educação em sentido amplo é, pois, a porta de entrada para a discussão dos direitos das crianças como sujeitos singulares do MST. A análise da literatura a respeito da educação no MST indica que ela tem um duplo sentido: o da conquista de condições de vida para famílias trabalhadoras do campo e como parte da luta pela construção do projeto socialista de sociedade.

A vivência na pele e sem recursos de proteção, especialmente da violência e da pobreza, constitui a experiência de ser criança Sem Terra (BARROS, 2013, p. 34). Assim, ao discutir a participação e a luta por direitos dessas crianças, é importante considerar sua inserção em um movimento de luta pela terra e pela transformação da sociedade, em uma experiência social que busca formar, nas crianças, subjetividades que incorporem a luta pela terra como parte da prática social de seu grupo de pertencimento, ou seja, as infâncias do campo (BARROS, 2013).

O MST, ao mesmo tempo em que luta por educação escolar, formula uma pedagogia específica para a infância, desenvolvendo publicações dirigidas às crianças, como o Jornal e a Revista Sem Terrinha. Barros (2013) identifica a emergência de uma preocupação com a educação das crianças pelo MST a partir da demanda de que as crianças tivessem espaço específico para suas atividades nos congressos do Movimento, o que levou à criação das Cirandas Infantis.

As Cirandas Infantis cumpririam duas funções: a de proporcionar a continuidade das aprendizagens escolares interrompidas para a participação das famílias e suas crianças no Congresso e a de favorecer sua organização específica no Movimento (BARROS, 2013). 
Nessa direção, a participação é uma categoria central, pois, ao favorecer a participação, o MST espera que as crianças se formem para tomar parte na luta pela terra - o que não significa uma ação exclusivamente para o futuro.

A criança é concebida como agente que atua ao lado dos adultos na luta por escolas, na implantação das chamadas escolas itinerantes e são sujeitos de uma educação que visa a fortalecer a identidade Sem Terra e a pertença ao MST (BARROS, 2013). Observa-se a concepção da criança como sujeito político, embora, em última instância, são as lideranças adultas que criam os espaços e definem seus objetivos. Assim, a apreensão da ação coletiva de crianças não pode prescindir da análise das relações intergeracionais em um processo de mútuo reconhecimento e reciprocidade (MELUCCI, 1996).

O MST organiza as Cirandas Infantis e Encontros dos Sem Terrinha, que são espaços de educação nos quais são proporcionadas às crianças experiências de reflexão sobre as condições de vida dos Sem Terra e a condição das crianças desse grupo, inclusive promovendo o conhecimento do ECA.

Nessas experiências, por meio de diferentes linguagens, as crianças manifestam seus pontos de vista a respeito de sua condição e a relação com os adultos, produzindo manifestos dirigidos ao próprio MST ou a outros segmentos sociais e ao poder público (ROSSETO, 2009). As ações de comunicação, de um modo geral, contam com equipe composta pelos militantes adultos, que as viabilizam. São produzidas também publicações, contendo entrevistas com as crianças, textos, desenhos e ilustrações produzidos por elas (BARROS, 2013).

Em estudo acerca do I Encontro Nacional de Crianças Sem Terrinha, Gouvea et al., (2019) analisaram como, em certos aspectos, o evento reproduziu as dinâmicas do Movimento adulto, ao centrar-se em atividades plenárias, dificultando a manifestação e a escuta das crianças. Esse elemento revela ainda contradições e limites da participação infantil, mesmo quando as crianças são concebidas como sujeitos de direitos. Como afirma Liebel (2012), em sua análise dos movimentos de crianças trabalhadoras na América Latina, as formas de comunicação das crianças são mais pragmáticas e menos discursivas, aliando lazer e reflexão, de forma mais ágil, sem, no entanto, perderem a eficácia.

A agência das crianças também é observada em pesquisas que focalizam o cotidiano. Em estudo que discute as várias formas de participação de crianças de 7 a 10 anos de um assentamento rural e da periferia urbana do mesmo município, Carvalho e Silva (2013, p. 96) discutem a participação a partir das condições de vida observadas. As autoras afırmam que "não há espaço para a não participação, mas sim para o entendimento das formas diferentes de posicionar-se no jogo das relações sociais”. Elas problematizam a participação nas diferentes interações das crianças com adultos e entre elas, desvelando tanto situações de inserção na vida familiar e na vida produtiva do assentamento, quanto entre as crianças em suas brincadeiras. Nessa perspectiva, o estudo identifica a participação das crianças na casa e na escola, descritas como ações tanto de colaboração quanto de influência e de resistência na distribuição das responsabilidades. Para as autoras:

[...] em alguns momentos, são atualizadas formas bastante tradicionais de relação etária, de controle do adulto sobre a criança; em outros, verifica-se a emergência de sujeitos crianças empoderados e em situação de igualdade em relação ao sujeito adulto. (CARVALHO; SILVA, 2013, p. 111). 
Outros trabalhos também enfatizam a presença de crianças na luta política como uma condição decorrente da sua presença nas famílias acampadas ou assentadas (ALVES, 2001 apud ROSSETO, 2009, p. 80). Embora as crianças não participem da tomada de decisões, elas acompanham seus pais e presenciam as situações de preparação para as ocupações de terras, o que envolve tensões e transformações no seu cotidiano.

Se há características da experiência das crianças do MST difíceis de serem encontradas em outros ambientes urbanos ou rurais, não há homogeneidade de experiências. Essas dependem do contexto material e simbólico, incluídas as marcas das relações de poder. Só é possivel problematizar a noção de direitos das crianças ligadas ao MST e que assumem a identidade Sem Terrinha, a partir da consideração de que elas participam de processos de formação e são incentivadas à ação política em nome dos fundamentos da luta do movimento pela terra e pela transformação social.

Parece adequado ampliar a noção de participação, incluindo a consideração de suas múltiplas formas que se apresentam como colaboração, influência e resistência na circulação e distribuição hierárquica ou igualitária de responsabilidades (CARVALHO; SILVA, 2013). A presença das crianças nas lutas por direitos não assegura, necessariamente, a participação nas tomadas de decisão, mas a promove, à medida que são colocadas em situações de reflexão sobre as opressões, e ao mesmo tempo em que, nesse processo, são tensionadas hierarquias intergeracionais.

\section{Considerações finais}

$\mathrm{Na}$ análise da participação das crianças em duas ações coletivas, buscamos compreender o significado de fazer os direitos das crianças em sua vida cotidiana, de modo a apreender as tensões entre formulações globais e locais de direitos (REYNOLDS; NIEUWENHUYS; HANSON, 2006; LIEBEL, 2012).

A participação das crianças no MNMMR ocorreu em um momento de redemocratização do país e de conquista de direitos, em que o Movimento centrou esforços na elaboração e aprovação do ECA, perdendo força, posteriormente. No caso do MST, seu crescimento ocorreu em um período posterior (2003 a 2016), quando o Movimento construiu parcerias com o Estado, garantindo sua institucionalidade e permanência.

A participação infantil assumiu também sentidos singulares. 0 MNMMR afirmou, como princípio, a participação direta dos meninos e meninas em situação de rua, favorecendo que, com o apoio de educadores sociais, assumissem protagonismo nas ações relacionadas ao processo de construção dos direitos da criança no Brasil. A condição de mobilidade, com menor controle adulto, possibilitou que construíssem domínio dos espaços públicos, relações sociais ampliadas e o direito à gestão de suas vidas, em processos de reflexão entre eles e com os adultos, rompendo com uma perspectiva que contrapõe autonomia e proteção. Nessa direção, consideramos que a condição de ator social (TOURAINE, 1996; MARCHI; SARMENTO, 2017) se revelou de forma mais evidente no contexto de superação do lugar de vítima para o lugar de sujeito que luta coletivamente por seus direitos. Evidentemente, o protagonismo infantil é tensionado pelas relações hierárquicas de poder entre adultos e crianças, tanto na organização e gestão dos movimentos quanto na legitimação dos discursos. 
Já no caso dos Sem Terrinha, embora em condições mais protegidas pelas famílias e lideranças do MST, a situação de poderem se organizar em um processo de reflexão sobre seus direitos internamente às suas comunidades e, especialmente, em relação aos direitos das crianças e adolescentes assegurados pelo ECA, possibilita a essas crianças a construção de identidade de criança pertencente a um movimento social de luta e a um modo de produção e reprodução da vida, marcado pelas experiências de ocupar e conquistar a terra. A construção de pautas próprias, ainda que com a colaboração de educadores e educadoras, favorece a identidade de atores coletivos na reflexão e luta por seus direitos, à medida que os princípios que orientam tais ações educativas se ancoram em concepções de educação emancipatória. Cabe observar que os estudos revelam limites nas possibilidades de expressão efetiva dos pontos de vista das crianças, especialmente no que se refere às linguagens infantis.

Ainda quanto ao princípio da proteção, observa-se a proteção não em caráter individual, conforme elaborado na CDC. Esse princípio é submetido à lógica dos movimentos sociais. Os dois movimentos tensionam as normativas e práticas que privilegiam a proteção em detrimento da ação desses sujeitos. Tal tensão talvez indique ser possível caminhar para maior equilíbrio entre as duas dimensões do direito: o da proteção e o da possibilidade de ação como ator coletivo.

Quanto à governança dos direitos, os dois Movimentos buscam construir uma autonomia na relação com o Estado e, ao mesmo tempo, demandam do poder público condições materiais e institucionais de sustentação de suas ações, mobilizando atores e instituições.

Ambos os Movimentos apresentam projetos educacionais que tensionam e procuram ultrapassar os limites das pedagogias próprias da escola regular. 0 projeto educacional do MNMMR funda-se em uma pedagogia embasada nos pressupostos de Paulo Freire, com o desenvolvimento de uma educação social que aliou a criação de condições para o retorno às famílias e a inserção na escola regular, junto às demais crianças. Já o MST buscou formular um projeto diferenciado de escola, que valoriza a identidade cultural e saberes sobre agricultura e sustentabilidade, mantendo uma visão de educação que ultrapassa a educação escolar, reconhecendo-a nas diversas experiências das crianças e adultos nas ações coletivas.

Observa-se, nos dois casos, a realização de uma lógica horizontal na governança dos direitos, em que adultos e crianças mobilizam agentes e instâncias no debate e na reivindicação de direitos. Ainda que circunscritos a lógicas de organização e modelos adultocentrados, a presença de crianças na cena social inaugura, no contexto brasileiro, uma perspectiva de governança do direito, com presença e participação from below das crianças, nos controversos papéis de sujeitos e de objetos de poder.

As teorizações dos estudos dos movimentos sociais e de ações coletivas demonstram que os conceitos de ator, agência e participação não podem ser tomados como pressupostos apriorísticos, mas que demandam análise das condições e contradições para sua efetivação. Assim é que o conceito de ator social remete a uma racionalidade e à possibilidade de subjetivação, que demanda ser problematizadas ao discutir a participação das crianças em ações coletivas. Em que medida tal racionalidade, nos termos em que é definida, não desconsidera as expressões distintas da racionalidade infantil? Como a autonomia 
do sujeito é pensada em relação à criança, necessariamente inserida em uma ordem geracional que a tensiona?

Acreditamos que a análise das experiências de participação da criança nessas duas ações coletivas indica a necessidade de avanço nas teorizações, tanto no campo dos estudos da infância quanto dos movimentos sociais e ações coletivas, o que buscamos, ainda que de forma preliminar, contemplar neste texto.

\section{Referências}

ARAÚJO, Maria Nalva Rodrigues de. As contradições e as possibilidades de construção de uma educação emancipatória no contexto do MST. 2007. 334 f. Tese (Doutorado em Educação) Universidade Federal da Bahia, Salvador, 2007.

ASSIES, Willem. De movimientos estructurados y estructuras en movimiento. Una visión general de las perspectivas teóricas sobre los movimientos sociales. Tabula Rasa, Bogotá, n. 25, p. 45-149, jul./dez. 2016.

BARROS, Monyse Ravena de Souza. Os Sem Terrinha: uma história de luta social no Brasil (1981-2012). 2013. 228 f. Dissertação (Mestrado em História Social) - Universidade Federal do Ceará, Fortaleza, 2013.

BRASIL. Lei 8069/1990. Dispõe sobre o Estatuto da Criança e do Adolescente e dá outras providências. Brasília, DF: Senado Federal: Coordenação de Edições Técnicas, 1990.

BRASIL. Lei 13257/2016. Dispõe sobre as políticas públicas para a primeira infância e altera a Lei $n^{0}$ 8.069, de 13 de julho de 1990 (Estatuto da Criança e do Adolescente), o Decreto-Lei nº 3.689, de 3 de outubro de 1941 (Código de Processo Penal), a Consolidação das Leis do Trabalho (CLT), aprovada pelo Decreto-Lei $n^{0} 5.452$, de $1^{\circ}$ de maio de 1943, a Lei $n^{0} 11.770$, de 9 de setembro de 2008, e a Lei $n^{0}$ 12.662, de 5 de junho de 2012. Diário Oficial da União, Brasília, DF, Seção 1, p. 1, 2016.

CARVALHO, Regiane S.; SILVA, Ana Paula S. Crianças assentadas: o que dizem sobre a participação na família e na escola? In: SILVA, Isabel de 0.; SILVA, Ana Paula S.; MARTINS, Aracy A. Infâncias do campo. Belo Horizonte: Autêntica, 2013. p. 93-113.

COHN, Gabriel. Max Weber. São Paulo: Ática, 1979.

CORREIA, Luciana Oliveira; GIOVANETTI, Maria Amélia Gomes de Castro; GOUVÊA, Maria Cristina Soares de. Movimentos sociais e experiência geracional: a vivência da infância no Movimento dos Trabalhadores sem Terra. Educação em Revista, Belo Horizonte, n. 46, p. 143-166, dez. 2007.

COSTA, Claudio Fernandes. Educação e cidadania: o Estatuto da Criança e do Adolescente. In: BAZÏLIO, Luiz; EARP, Maria de Lourdes (org.). Infância tutelada e educação: história, políticas e legislação. Rio de Janeiro: Ravil, 1998. p. 161-171.

DIMENSTEIN, Gilberto. Meninas da noite. São Paulo: Ática, 1992.

DOIMO, Ana Maria. Movimento popular no Brasil pós-1970: formação de um campo ético-político. 1993. Tese (Doutorado em Ciência Política) - Universidade de São Paulo, São Paulo, 1993. 
FALEIROS, Eva Terezinha Silveira. A criança e o adolescente: objeto sem valor no Brasil Colônia e no Império. In: PILOTTI, Francisco; RIZZINI, Irene (org.). A arte de governar crianças: a história das políticas sociais da legislação e da assistência a infância no Brasil. Rio de Janeiro: Santa Orsula, 1995. p. 33-96.

FERGUSON, Lucinda. Not merely rights for children but children's rights: the theory gap and the assumption of the importance of children's rights. International Journal of Children's Rights, Leiden, v. 21, n. 2, p. 177-208, 2013.

FREITAS, Fábio Accardo de. Educação infantil popular: possibilidades a partir da Ciranda Infantil do MST. 2015. 228 f. Dissertação (Mestrado em Educação) - Universidade Estadual de Campinas, Campinas, 2015.

GOHN, Maria da Glória Marcondes. A força da periferia: a luta das mulheres por creches em São Paulo. Petrópolis: Vozes, 1985.

GOHN, Maria da Gloria Marcondes. Teoria dos movimentos sociais. São Paulo: Loyola, 1998.

GOUVEA, Maria Cristina Soares et al. 0 protagonismo infantil no interior de movimentos sociais contemporâneos no Brasil. Sociedad e Infancias, Madrid, v. 3, p. 21-63, 2019.

HUGHES, Nancy Scheper; HOFFMAN, Daniel. Moving Targets: Street Kids. Natural History Magazine, Carolina do Norte, v. 106, n. 6, p. 34-43, 1997.

JAMES, Allison; PROUT, Alan. Constructing and reconstructing childhood. London: Routledge, 2015.

LADRIĖRE, Jean. La philosophie sociale: la philosophie contemporaine. Firenze: La Nueva Italia, 1971.

LAZZARETTI DE SOUZA, Ana Paula et al. Participação social e protagonismo: reflexões a partir das conferências de direitos da criança e do adolescente no Brasil. Avances en Psicologia Latino Americana, Bogotá, v. 28, n. 2, p. 178-193, 2010.

LEE, Nick. Childhood and society: growing up in an age of unccertainly. Buckingham: Open University, 2001.

LIEBEL, Manfred (org.). Children's Rights from Below: cross-cultural perspectives. London; New York: Palgrave Macmillan, 2012.

MARCHI, Rita de Cássia; SARMENTO, Manuel Jacinto. Infância, normatividade e direitos das crianças: transições contemporâneas. Educação \& Sociedade, Campinas, v. 38, n. 141, p. 951-964, out./dez. 2017.

MAYALL, Barry. Towards a sociology of childhood. Buckingham: Open University, 2002.

MELUCCI, Alberto. Challenging codes: collective action in the information age. Cambridge: Syndicate of the University of Cambridge, 1996.

MILNE, Brian. Rights of the child: 25 years after the adoption of the UN Convention. Heidelberg: Springer, 2015.

MIRANDA, Edna Lopes; FIÚZA, Ana Louise C. Movimentos sociais rurais no Brasil: o estado da arte. Revista de Economia e Sociologia Rural, Piracicaba, v. 55, n, 01, p. 123-136, jan./mar. 2017. 
MNMMR. Movimento Nacional de Meninos e Meninas de Rua. Cartilha. São Paulo: 2005.

MNMMR. Movimento Nacional de Meninos e Meninas de Rua. Cidadão criança, cidadão adolescente: contribuição para a definição de uma política para a infância e juventude no Brasil. Brasília, DF: MNMMR, 1990.

MNMMR. Movimento Nacional de Meninos e Meninas de Rua. Dez anos de Movimento Nacional de Meninos e Meninas de Rua 1985/1995. Brasília, DF: Unicef, 1995.

OLIVEIRA, Ana Cynthia; HADDAD, Sérgio. As organizações da sociedade civil e as ONGs de educação. Cadernos de Pesquisa, São Paulo, n. 112, p. 61-83, mar. 2001.

PARGA, José Sanchez. Orfandades infantiles y adolescentes: introducción a una sociología de la Infáncia. Quito: Abya-Yala, 2004.

PEREIRA, Antonio. A educação no Movimento Nacional de Meninos e Meninas de Rua (MNMMR): a contribuição do Projeto Axé na legitimação da pedagogia social de rua. Educação em Revista, Marília, v. 12, n. 2, p. 125144, jul./dez. 2011.

PILOTTI, Francisco. Globalización y convención sobre los derechos del niño: el contexto del texto. New York: Unesco, 2000.

PILOTTI, Francisco; RIZZINI, Irene (org.). A arte de governar crianças. Rio de Janeiro: Universitária Santa Úrsula, 1995.

QUENNERSTEDT, Ann. Children's rights research moving into the future: challenges on the way forward. International Journal of Children's Rights, Leiden, v. 21, n. 3, p. 233-247, 2013.

QVORTRUP, Jens; CORSARO, William A.; HONIG, Michael-Sebastian. (Ed.). Palgrave handbook of Childhood Studies. Basingstoke: Palgrave Macmillan, 2010.

REYNOLDS, Pamela; NIEUWENHUYS, Olg; HANSON, Karl. Refractions of children's rights in development practice: a view from anthropology: introduction. Childhood 13, Oslo, n. 3, p. 291-302, 2006.

ROSEMBERG, Fúlvia. 0 discurso sobre criança de rua na década de 1980. Cadernos de Pesquisa, São Paulo, n. 87, p. 71-81, nov. 1993.

ROSEMBERG, Fúlvia; MARIANO, Carmem Lúcia Sussel. A Convenção Internacional sobre os Direitos da Criança: debates e tensões. Cadernos de Pesquisa, São Paulo, v. 40, n. 141, p. 693-728, set./dez. 2010.

ROSSETO, Edna R. A. A organização do trabalho pedagógico nas cirandas infantis do MST: lutar e brincar faz parte da escola de vida dos Sem Terrinha. 2016. 270 f. Tese (Doutorado em Educação) Universidade Estadual de Campinas, Campinas, 2016.

ROSSETO, Edna R. A. Essa ciranda não é minha só, ela é de todos nós: a educação das crianças sem terrinha no MST. 2009. 222 f. Dissertação (Mestrado em Educação) - Universidade Estadual de Campinas, Campinas, 2009. 
SADER, Eder; PAOLI, Maria Célia. Sobre "classes populares" no pensamento sociológico brasileiro (Notas de leitura sobre acontecimentos recentes). In: CARDOSO, Ruth (org.). A aventura antropológica: teoria e pesquisa. Rio de Janeiro: Paz e Terra, 1986. p. 39-67.

SANTOS, Sandro V. S.; SILVA, Isabel de 0. Crianças na educação infantil: a escola como lugar de experiência social. Educação e Pesquisa, São Paulo, v. 42, n. 1, p. 131-150, jan./mar. 2016.

SPYROU, Spyros. Disclosing childhoods. London: Palgrave, 2018.

SUDBRACK, Umberto Guaspari. 0 extermínio de meninos de rua no Brasil. São Paulo em Perspectiva, São Paulo, v. 18, n. 01, p. 22-30, 2014. Disponível em: http://produtos.seade.gov.br/produtos/spp/v18n01/ V18n1_03.pdf. Acesso em: 04 abr. 2021.

TOBIN, John. Justifying children's rights. The International Journal of Children's Rights, Leiden, v. 21, n. 3, p. 395-441, 2013.

TOURAINE, Alain. As classes sociais na América Latina. Rio de Janeiro: Paz e terra, 1997.

TOURAINE, Alain. 0 retorno do actor: ensaio sobre sociologia. Lisboa: Instituto Piaget, 1996.

UNICEF. Fundo das Nações Unidas para a Infância. Convenção Internacional dos Direitos da Criança. Brasília, DF: Unicef, 2019.

UNICEF. Fundo das Nações Unidas para a Infância. To light a candle: what was attempted and what happened. Brasília, DF: Unicef,1987. Final report of street children estimatives.

Recebido em: 30.04.2020

Revisado em: 01.09.2020

Aprovado em: 24.11.2020

Maria Cristina Soares de Gouvêa é professora titular da Faculdade de Educação e do Programa de Pós-Graduação em Educação da Universidade Federal de Minas Gerais (UFMG). É pesquisadora do Núcleo de Estudos e Pesquisas em Infância e Educação Infantil (NEPEI), da UFMG.

Levindo Diniz Carvalho é professor adjunto da Faculdade de Educação e do Programa de Pós-Graduação em Educação da Universidade Federal de Minas Gerais (UFMG). É pesquisador do Núcleo de Estudos e Pesquisas em Infância e Educação Infantil (NEPEI), da UFMG.

Isabel de Oliveira e Silva é professora associada da Faculdade de Educação e do Programa de Pós-Graduação em Educação da Universidade Federal de Minas Gerais (UFMG). É pesquisadora do Núcleo de Estudos e Pesquisas em Infância e Educação Infantil (NEPEI), da UFMG. 